\title{
Effect of debris size on the tribological performance of thermally sprayed coatings
}

\author{
K.A. Habib ${ }^{1}$, D.L. Cano ${ }^{1}$, José Antonio Heredia ${ }^{1}$, Ángel Vicente-Escuder ${ }^{2}$ \\ 1) Department of Industrial System Engineering and Design, Universitat Jaume I, \\ 12071 Castellón, Spain. \\ 2) Department of mechanical Engineering and Materials, Universidad Politécnica de Valencia \\ Corresponding author: Tel.: +34-964-728195 ; Fax: +34-964-728170; address: razzaq@esid.uji.es
}

\begin{abstract}
This research aims to assess the effect of the debris particle size on the tribological performance and lubrication regime parameters of a Ni-based alloy coating. This is a key industrial problem, and its resolution can contribute to better machine endurance and proper maintenance.

The debris particles are simulated by hard $\mathrm{Al}_{2} \mathrm{O}_{3}$ particles of size ranging from nanometers to 45 $\mu \mathrm{m}$ and dispersed in an oil lubricant. The coating studied is NiCrBSi deposited by flame spraying technique followed by the Surface Flame Melting (SFM) process. The counterpart disk sample was fabricated from quenched and tempered F-5220 steel (in line with A681(O1) ASTM). This pair was tested under linear sliding contact.

Our results show that the addition of alumina particles contributes to a significant increase in wear, particularly for the largest particles (micrometric size). In the case of micrometric particles, it is possible to observe the formation of higher surface roughness, numerous microgrooves, and plastic flow of NiCrBSi coating perpendicular to the sliding direction, resulting in higher loss of volume.

It was found that the actual surface roughness (obtained as a function of the debris particle size) allows better identification and prediction of the lubrication regime for wear processes instead of the traditional approach that uses the initial surface roughness as a parameter.
\end{abstract}

Keywords: tribological performance, surface roughness, debris particle size, lubrication regime parameters, NiCrBSi coatings

\section{Introduction}

Wear of machinery components can be reduced by depositing coatings on the surfaces in contact and by applying lubricants [1,2]. Although many critical components (for instance in aeronautic and automotive industry) use coatings [3,4], due to the fact that most lubricant producers have developed their products such as to optimize their tribological behavior on substrates, separate studies are necessary to examine the specific lubricant-coating pair behavior [5],[6],[7]. 
The thickness of the lubricant film in relation to the separation between the surfaces defines the lubrication regime. Friction and wear is reduced to a minimum if the lubricant layer prevents physical contact between the asperities of the surfaces. This is called hydrodynamic lubrication regime. However, practical applications usually involve rigorous operational conditions with application of high load, pressure, and temperature, which cause the surface asperities to come into contact at some point; thus, the machine components usually work in a mixed lubrication regime.

Contact between surfaces causes detachment of particles, which contaminate the lubricant medium. The solid particles suspended in lubricating oil are called debris and they are a major problem in most industries. Apart from these internally generated particles, the lubricating oil may be contaminated with other particles from the outside environment, such as dust particles or soot typical in the engines of vehicles. The problem of particle contamination from the outside is especially serious in machines operating in dusty environments [8]. In these conditions, filters are applied to reduce the problem but these filters cannot prevent the passage of small particles (many of which are in the nanoscale). Trapping of such small particles by the filter can cause the filter to be plugged, which can generate inadmissible pressure losses [9]. Research on methods to improve the wear resistance of machinery parts under conditions of lubrication contaminated with abrasives is of high priority and of great industrial importance [10].

The presence of debris in the lubricating media has been widely studied, as it is very important in understanding the phenomenon of wear. Consequently, condition-based maintenance methods have utilized the relationship between the size, quantity, and shape of the debris particles and the state of deterioration of the component [11], [12],[13]. Condition-based maintenance is essential to maintain and extend the health of components that operate at high speeds, such as machinery in the key industries of aerospace, automotive, energy, or machine tools. Currently, the emphasis of research and development in this area is on the development of sensors and methods to evaluate the debris characteristics in real time and use these data to predict the health status of the component [14].

Although it is difficult to generalize the relationship between the deterioration of the machinery and the debris particle size because it is specific to a case, greater quantity of debris and larger debris size usually implies greater deterioration of the machinery. Fig. 1 represents the usual model [15] that serves as a reference to relate the distribution of size and concentration of the debris as a function of the time of use of the machinery. 


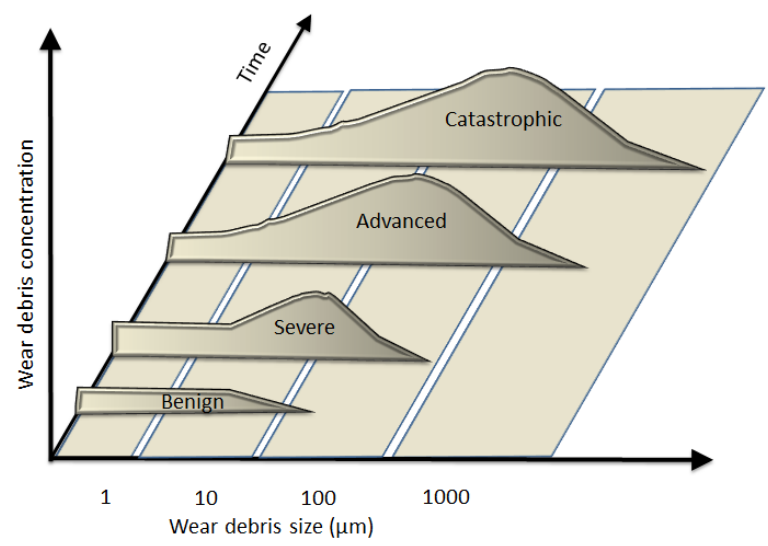

Figure 1. Relation between debris size and quantity with machine utilization time. Adapted from [15].

Numerous studies on many components (motors, gearboxes, bearings, gears, etc.) have found that the size and quantity of the debris increases gradually with time of use until eventual failure [16], [17],[18]. Depending on each application, a certain critical average size of the debris may indicate that the machine is in an advanced condition of deterioration and therefore an intervention is required to avoid a catastrophic failure [19].

The presence of debris in the lubricating medium increases the friction owing to the force necessary to drag the particles along the surfaces in contact, and causes greater wear especially due to ploughing by the particles [20]. These effects are more severe under the conditions of high pressure and speed, such as with rolling elements [21]. As the amount and size of the debris increases, the phenomenon of third-body abrasive wear occurs [22]. Although most studies show that greater quantity and size of debris are indicative of increased friction and wear, it should be noted that under certain tribological conditions, especially under low-pressure conditions, certain phenomena contribute to reducing the friction in the presence of debris. Thus, some studies show that the presence of debris can generate a protective layer and reduce the friction by generating a tribolayer. The small particles of debris, preferably of spherical shape, can perform the function of nano or micro-bearings by distributing the pressure between the surfaces in contact [23],[24]. Another phenomenon that can occur at low pressures and high speed is that the increase in viscosity of the lubricant created by the particles generates a greater hydrodynamic separation force between the surfaces in contact ("skid effect"). Therefore, a review of the state-of-the-art literature shows that the influence of debris on friction and wear depends on the tribological conditions.

To enhance the knowledge of the mechanisms of wear in lubricated media, it is important to assess the relationship between the size of the particles and the lubrication regime. This knowledge would allow us to estimate the friction under a specific working condition for a given type of lubricant and specific materials in contact. 
The Stribeck curve demonstrates the evolution of friction with the basic characteristics of the tribological system: pressure, speed, viscosity of the lubricant, and roughness. Surface roughness was defined by Schipper as a key element affecting the lubrication regime [25]. In a system where the surface roughness does not change, it is logical to consider the initial surface roughness. However, we propose to use the actual roughness to evaluate the tribological behavior that eventually leads to failure. In this paper, we introduce a new parameter based on the actual roughness instead of the initial roughness, which makes it more representative of the usual state of operation of the surface under study.

The objective of this research is twofold: to study the influence of debris particle size on the tribological behavior of a Ni-based coating and to propose a general method to predict the lubrication regime according to the size of the debris particles present in the lubricant.

The study uses highly abrasive particles to simulate the most unfavorable conditions under which the debris has greater hardness than the surfaces in contact and presents an irregular geometry. To evaluate the effect of size, we carried out experiments with three different sizes of alumina particles: nanometric size of $1.5 \mu \mathrm{m}$, and micrometric sizes of $32.5 \mu \mathrm{m}$ and $45 \mu \mathrm{m}$.

\section{Experimental Procedure}

\subsection{Materials}

According to ASTM G 99 test we made cylindrical pins of 18-mm length and 8-mm diameter. The pins were made of AISI 304 steel and the counterpart disk for the pin-on-disc test was hardened and tempered F-5220 steel (in line with A681 (01) ASTM) with average hardness of $930 \mathrm{HV}_{200 \mathrm{gf}}$. One end of the cylindrical specimens was coated with self-fluxing (standard commercial feedstock powder) alloy coating of NiCrBSi Amperit M-772.33 with the following chemical composition by weight: $0.3 \% \mathrm{C}, 3.52 \% \mathrm{Si}, 1.7 \% \mathrm{~B}, 7.71 \% \mathrm{Cr}, 2.66 \% \mathrm{Fe}$, and rest $\mathrm{Ni}$. Fig. 2 shows that the powder particles, which were used for coating the pin, have completely spherical morphology with average size range of $20-53 \mu \mathrm{m}$ and melting point of $1025{ }^{\circ} \mathrm{C}$. Micrometric- $\mathrm{Al}_{2} \mathrm{O}_{3}$ (PRAXAIR ALO-101, ALO-325 mesh) and nanometric- $\mathrm{Al}_{2} \mathrm{O}_{3}$ (NANOX S2600S) particles with different mean sizes and morphologies, shown in Fig 3, were used as the source of debris. These particles were dispersed in $10 \mathrm{ml}$ of lubricated oil. Reference tests were performed with only lubricated oil. 

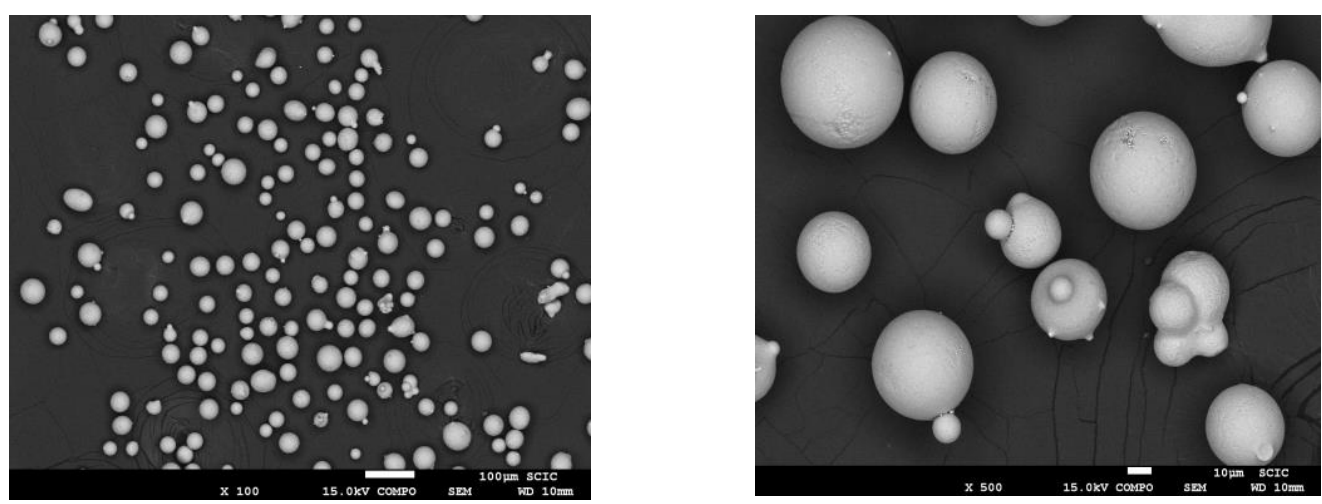

Figure 2. SEM of initial powder morphology of NiCrBSi coating at different magnifications.

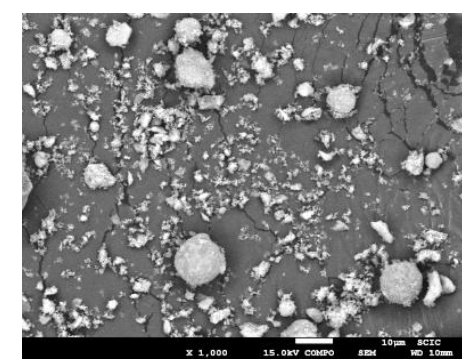

a)

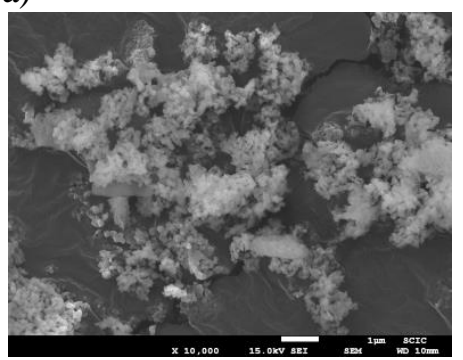

$\left.\mathrm{a}^{1}\right)$

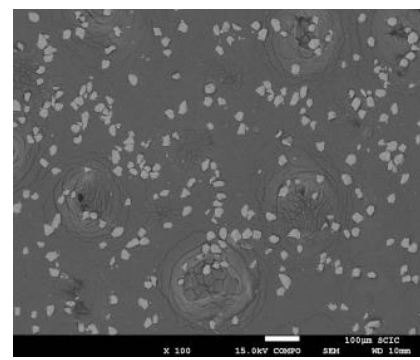

b)

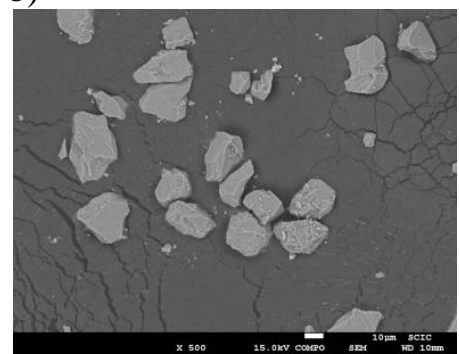

$\left.b^{1}\right)$

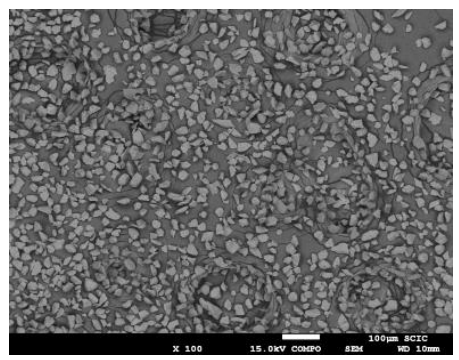

c)

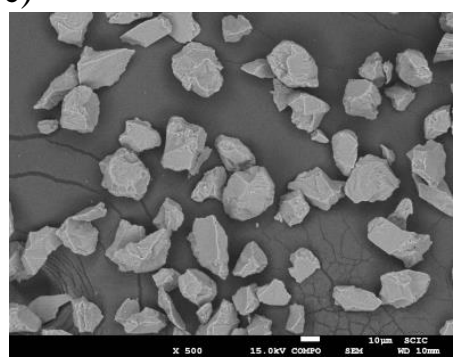

$\left.\mathrm{c}^{1}\right)$

Figure 3. SEM morphologies and distribution of $\mathrm{Al}_{2} \mathrm{O}_{3}$ particles used as debris source: a) nanosize, b) micro-size $(32.5 \mu \mathrm{m})$ and c) micro-size $(45 \mu \mathrm{m})$ at different magnifications.

\subsection{Flame-spray deposition}

Flame spraying using powder material as feedstock is one of the more versatile and less expensive thermal spraying techniques. Before the spraying, one end of the pin surface was gritblast using corundum abrasive particles of $99.6 \%$ purity and mean size of $0.53 \mathrm{~mm}$, blown under compressed air of $6 \mathrm{~kg} / \mathrm{cm}^{2}$ for one minute at incident angle of approximately $45^{\circ}$ and gun to substrate distance of $130 \mathrm{~mm}$. The substrate was preheated to approximately $150{ }^{\circ} \mathrm{C}$ and the NiCrBSi coating was deposited using CDS-8000 flame spray torch manufactured by Castolin Eutectic. The main parameters associated with the flame spraying process are shown in Table 1. After the deposition process, the pins were cleaned and degreased with acetone in an ultrasonic bath. 
Table 1. Thermal spray parameters

\begin{tabular}{ccccccc}
\hline $\begin{array}{c}\text { Torch } \\
\text { speed } \\
(\mathrm{mm} / \mathrm{s})\end{array}$ & $\begin{array}{c}\mathrm{N}^{\mathrm{o}} \text { of } \\
\text { strokes }\end{array}$ & $\begin{array}{c}\text { Distance } \\
(\mathrm{mm})\end{array}$ & $\begin{array}{c}\text { Acetylene } \\
\text { Pressure } \\
(\mathrm{bar})\end{array}$ & $\begin{array}{c}\text { Oxygen } \\
\text { pressure } \\
(\mathrm{bar})\end{array}$ & $\begin{array}{c}\text { Air pressure } \\
(\text { bar })\end{array}$ & Flame type \\
\hline 67.5 & 6 & 130 & 0.7 & 4 & 2.5 & Neutral \\
\hline
\end{tabular}

After thermal spraying, the coated material was fused using the Surface Flame Melting (SFM) process with an oxyacetylene torch with an operating temperature of up to $1025{ }^{\circ} \mathrm{C}$ and a scanning speed of approximately $150 \mathrm{~mm} / \mathrm{min}$. After cooling at room temperature the NiCrBSi coatings were polished to average surface roughness of $R_{a}=0.016 \mu \mathrm{m}$. The resulting coatings thickness was around 1.100-mm.

\subsection{Lubricating oil and tribology tests}

Tribology tests were conducted on a tribometer with pin-on-disk configuration (TE79/P, Plint and Partners) at room temperature (temperature $\mathrm{T}=25^{\circ} \mathrm{C}$, humidity $\sim 55 \%$ ). Ten drops per minute of mineral oil, CUT-MAX 7-26, with viscosity of $100 \pm 0.1 \mathrm{cSt}$ at $40^{\circ} \mathrm{C}$ and density of 0.880 $\mathrm{gr} / \mathrm{cm}^{3}$ at $25^{\circ} \mathrm{C}$ were provided. Each one of the frictional tests was conducted at a constant load, starting from $0.037 \mathrm{~m} / \mathrm{s}$ and was increased every $3 \mathrm{~min}(20-\mathrm{m}$ distance) in a stepwise manner $(0.073,0.110,0.147,0.183)$ until the maximum speed of $0.22 \mathrm{~m} / \mathrm{s}$. The load was varied between $3,6,9,15$, and $20 \mathrm{~N}$.

\section{Results and discussion}

\subsection{Surface characterization}

\subsubsection{Study of worn surface}

In this study, a rugosimeter (HOMMELWERKE-T8000) has been employed to quantify the surface roughness of the NiCrBSi pin coating after test sliding distance of $600 \mathrm{~m}$ under different loads (up to $20 \mathrm{~N}$ ) and for each $\mathrm{Al}_{2} \mathrm{O}_{3}$ particle size (see Fig. 3) used as the source of debris. The perpendicular motion of the rugosimeter stylus with respect to the surface was recorded, and the recorded profile was then used to calculate the roughness parameters. It was observed that the surface roughness of the NiCrBSi coating pin lubricated solely with the lubricating oil was as low as $0.036 \mu \mathrm{m}$. However, the addition of $1.5 \mathrm{~g}$ of nanometric $\mathrm{Al}_{2} \mathrm{O}_{3}(1.5 \mu \mathrm{m}), 1.5 \mathrm{~g}$ of micrometric $\mathrm{Al}_{2} \mathrm{O}_{3}(32.5 \mu \mathrm{m})$, and $1.5 \mathrm{~g}$ of micrometric $\mathrm{Al}_{2} \mathrm{O}_{3}(45 \mu \mathrm{m})$ to the lubricants results in surface roughness values of $0.054,0.525$, and $1.967 \mu \mathrm{m}$, respectively.

An optical Surface Profiler (Sensofar PLu 2300), which enables the observations of topographic features in $3 \mathrm{D}$, was employed to evaluate the change in the topography of the pins with the NiCrBSi coating during lubrication tests. Fig. 3 shows the surface images of the NiCrBSi 
coatings and the roughness profiles of the surface rubbed under different loads and sliding velocities and sliding distance of up to $600 \mathrm{~m}$.

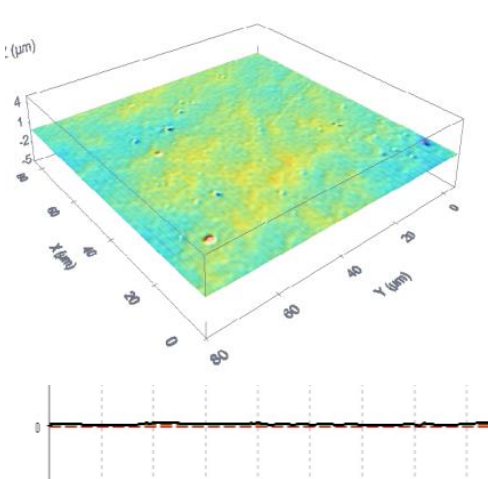

a) Initial roughness
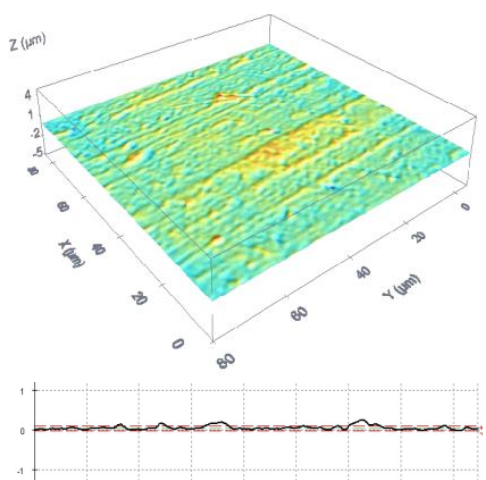

b) Solely oil

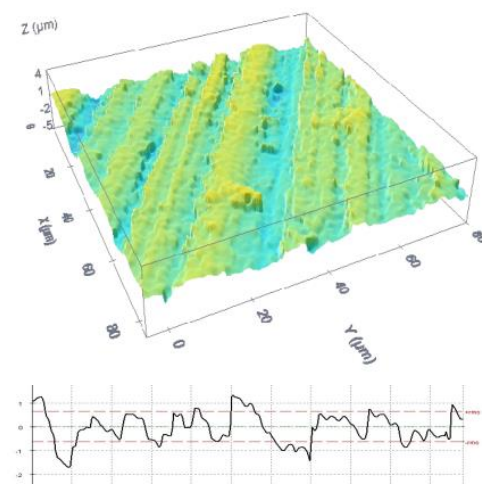

d) Oil+ $1.5 \mathrm{~g}$ micrometric $\mathrm{Al}_{2} \mathrm{O}_{3}$ $(32.5 \mu \mathrm{m})$.

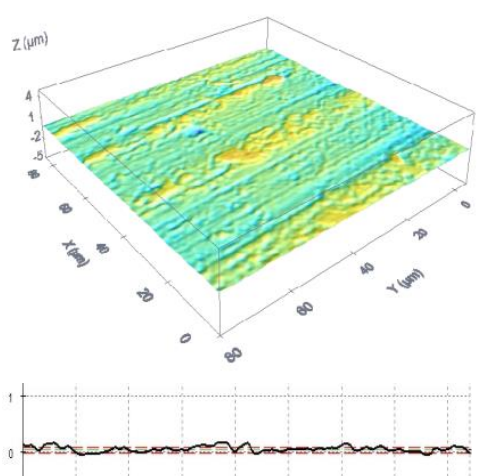

c) Oil + $1.5 \mathrm{~g}$ nanometric $\mathrm{Al}_{2} \mathrm{O}_{3}(0.15 \mu \mathrm{m})$

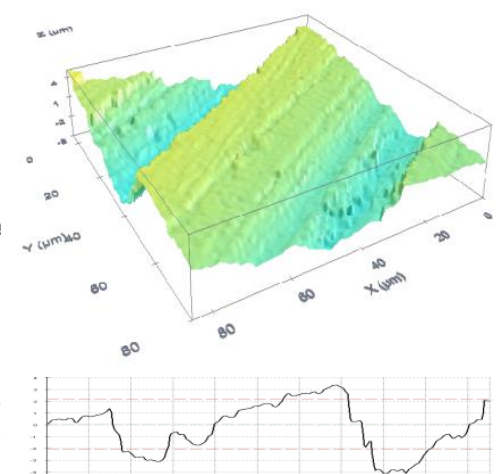

e) Oil $+1.5 \mathrm{~g}$ micrometric $\mathrm{Al}_{2} \mathrm{O}_{3}(45 \mu \mathrm{m})$

Figure 4. 3D Topographic map of the friction surfaces and surface roughness profile of the NiCrBSi pin coating after $600 \mathrm{~m}$ distance.

The 3D topographic maps show a central area of scars. The assessed length of each scar was the same. The addition of lubricating oil produced a small change in the wear scars (Fig. 4b) when compared with the initial surface roughness (Fig. 4a). Addition of $1.5 \mathrm{~g}$ of nanometric $\mathrm{Al}_{2} \mathrm{O}_{3}(0.15$ $\mu \mathrm{m})$ particles to the lubricated oil resulted in the appearance of nano scars on the NiCrBSi surface coating, as shown in Fig. 4c. Plough grooves, high scars, and severe deformation were observed on the surface samples after addition of $1.5 \mathrm{~g}$ of micrometric $\mathrm{Al}_{2} \mathrm{O}_{3}(32.5 \mu \mathrm{m})$ and micrometric $\mathrm{Al}_{2} \mathrm{O}_{3}(45 \mu \mathrm{m})$, as shown in Fig. $4 \mathrm{~d}$ and $4 \mathrm{e}$.

\subsubsection{SEM surface topography}

Surface topography observed in Fig. 4 was confirmed by SEM micrographs of the worn surfaces. Fig. 5 shows the morphologies of the worn surface after the tribology tests (sliding distance of $600 \mathrm{~m}$ ). Obvious differences in the surface morphologies are observed as a function of the $\mathrm{Al}_{2} \mathrm{O}_{3}$ particle size. The worn surfaces were observed by SEM to elucidate the influence of the $\mathrm{Al}_{2} \mathrm{O}_{3}$ particle size on the wear of the NiCrBSi coating. The worn pin surface coated with 
NiCrBSi exhibited different surface profiles across the wear scars after tribological tests with solely oil, oil $+1.5 \mathrm{~g}$ of nanometric $\mathrm{Al}_{2} \mathrm{O}_{3}(0.15 \mu \mathrm{m})$, oil $+1.5 \mathrm{~g}$ of micrometric $\mathrm{Al}_{2} \mathrm{O}_{3}(32.5 \mu \mathrm{m})$, and oil $+1.5 \mathrm{~g}$ of micrometric $\mathrm{Al}_{2} \mathrm{O}_{3}(45 \mu \mathrm{m})$.

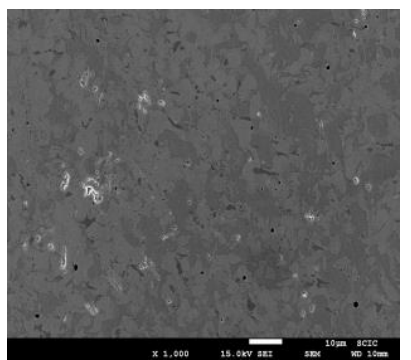

a)

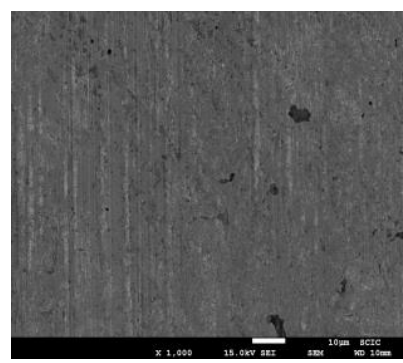

b)

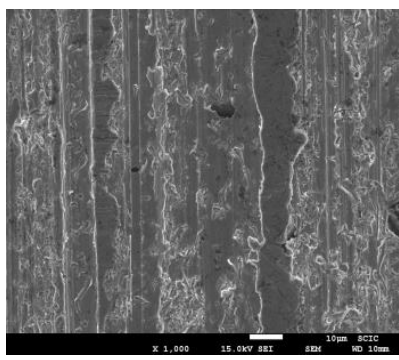

c)

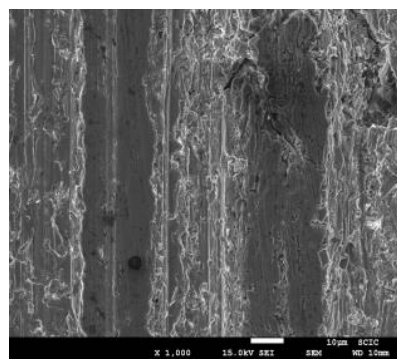

d)

Figure 5. SEM microstructures of worn surface of $\mathrm{NiCrBSi}$ pins exhibiting different morphologies: a) solely oil, b) oil $+1.5 \mathrm{~g}$ nanometric $\mathrm{Al}_{2} \mathrm{O}_{3}(0.15 \mu \mathrm{m})$, c) $1.5 \mathrm{~g}$ micrometric (32.5 $\mu \mathrm{m})$ and, d) oil $+1.5 \mathrm{~g}$ micrometric $\mathrm{Al}_{2} \mathrm{O}_{3}(45 \mu \mathrm{m})$.

Fig. 6a shows that the worn surface of the NiCrBSi coating with lubricated oil exhibits highly smooth surface and randomly scattered pits. In this case, the wear volume is limited but the surface roughness $\left(\mathrm{R}_{\mathrm{a}}\right)$ is slightly increased.

The wear mechanism of $\mathrm{NiCrBSi}$ with oil $+1.5 \mathrm{~g}$ of nanometric $\mathrm{Al}_{2} \mathrm{O}_{3}(0.15 \mu \mathrm{m})$ was governed by nano-cutting, exhibiting highly smooth surfaces with nano-scratches and no significant change in the surface morphology. Fig. $6 \mathrm{~b}$ shows ploughing tracks, which are probably associated with the dragging of agglomerated and compressed $\mathrm{Al}_{2} \mathrm{O}_{3}$ nanoparticles as well as wear debris at the interface, especially under high loads. Because of this effect, the surfaces rubbed with oil + nanometric $\mathrm{Al}_{2} \mathrm{O}_{3}(0.15 \mu \mathrm{m})$ are slightly rougher than the surfaces of the reference sample $\left(\mathrm{NiCrBSi}\right.$ coating + lubricating oil without $\mathrm{Al}_{2} \mathrm{O}_{3}$ ). The average values of the roughness parameter $\left(R_{\mathrm{a}}\right)$ for the reference test pin under steady state friction condition and different loads and velocities is 0.036 , whereas the corresponding value for the $\mathrm{NiCrBSi}$ pin tested with oil + nanometric $\mathrm{Al}_{2} \mathrm{O}_{3}$ is $0.054 \mu \mathrm{m}$.

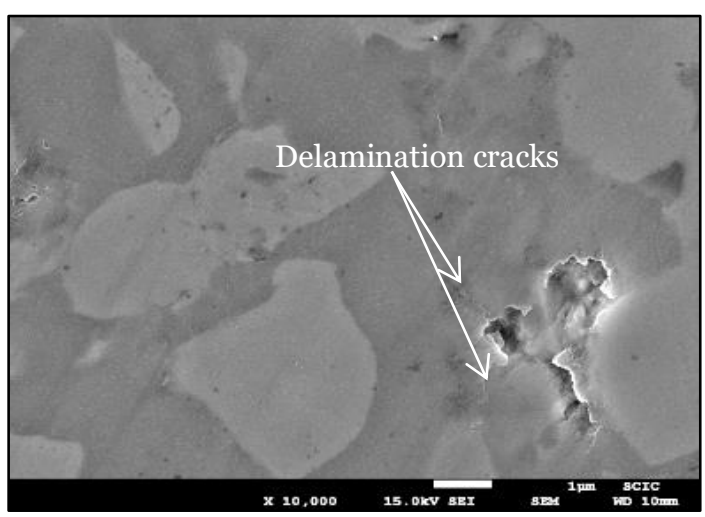

a)

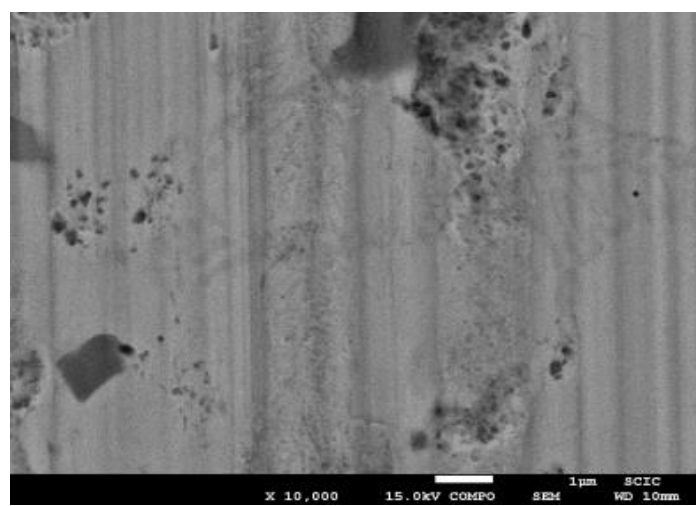

b)

Figure 6. Microstructure of the surface layer of $\mathrm{NiCrBSi}$ coating layers around the wear grooves after $600 \mathrm{~m}$ : a) solely oil and b) oil +1.5 nanometric $\mathrm{Al}_{2} \mathrm{O}_{3}$. 
Experiments with $\mathrm{Al}_{2} \mathrm{O}_{3}$ of $32.5 \mu \mathrm{m}$ show that the worn surface of $\mathrm{NiCrBSi}$ coating exhibited several plowing grooves coupled with noticeable plastic deformation along the edges of the wear scars (Fig. 7a). The dominant wear mechanism in the case of coating with $\mathrm{Al}_{2} \mathrm{O}_{3}$ of $45-\mu \mathrm{m}$ size was micro-cutting; a surface topography similar to the previous case, higher plastic deformation, and scratch tracks are also observed in this case (Fig. 7b). In both cases, change in the particle trajectory and the sample surface evolution generate cutting, indentation, and micro-deformation of the coating surface. The average values of the surface roughness after $600 \mathrm{~m}$ of sliding distance under different loads and sliding velocities were $0.525 \mu \mathrm{m}$ for $\mathrm{Al}_{2} \mathrm{O}_{3}$ of $32.5-\mu \mathrm{m}$ size and $1.96 \mu \mathrm{m}$ for $\mathrm{Al}_{2} \mathrm{O}_{3}$ of $45-\mu \mathrm{m}$ size, respectively.

The hard particles of $\mathrm{Al}_{2} \mathrm{O}_{3}$ entrapped between the moving surfaces are free to tumble and roll as well as slide through the gap between the interacting surfaces. The predominant wear mechanisms in each case are different. For smaller $\mathrm{Al}_{2} \mathrm{O}_{3}$ particles, indentations and microdeformations are formed by the collisions at high velocity whereas ploughing is caused by larger $\mathrm{Al}_{2} \mathrm{O}_{3}$ particles. The micrometric $\mathrm{Al}_{2} \mathrm{O}_{3}$ particles transported by the oil lubricant can pass easily through the dynamic clearance between the friction surfaces. SEM observations of the worn surface of the NiCrBSi coating indicate that severe indentation, micro-cutting, and ploughing occur in both cases. Indentations and micro-deformations are formed by the collisions and microrolling abrasion of medium and large $\mathrm{Al}_{2} \mathrm{O}_{3}$ particles at high velocities under the application of loads, whereas severe ploughing is caused by larger $\mathrm{Al}_{2} \mathrm{O}_{3}$ particles. Additionally, cutting mechanism is observed in both cases. This is due to the interaction between the $\mathrm{Al}_{2} \mathrm{O}_{3}$ particles and the NiCrBSi-coated surface at high velocity, and the cutting, indentation, and microdeformation can be caused by the change in the particle trajectory during the friction process. Fig. $7 \mathrm{a}$ and $\mathrm{b}$ show the magnified images of the wear crater, in which the occurrence of rolling abrasion along and parallel to the grooves is detected. The rolling marks are caused by round and slightly larger particles that are unable to enter the previously formed grooves, causing them to roll. The rolling or micro-rolling geometry and macro geometry is changed. Depending on the test conditions, rolling abrasion and grooving abrasion can occur simultaneously in a given crater. Additionally, round alumina particles dispersed in the oil lubricant randomly collide against the surface area of the friction pairs separated by the large particles, which can produce microdeformation due to the rolling of the medium and large particles and the kinetic energy of the small particles at high velocity.

Abrasive particles with sharp angles penetrate the coating surface depending on the applied load and the mechanical properties, form, dimensions, and sliding velocity of the contacting surfaces. These particles exercise some form of abrasive wear mode, such as micro-ploughing and micro-cutting. The penetration of a sliding abrasive particle into a metallic surface results in micro-ploughing or micro-cutting depending on the angle of attack [26]. Sliding of hard particles 
on metallic materials of less hardness can undergoes mainly elastic-plastic deformations depending on the angle of attack. These deformations occur around particles and spatially in front of their movement. In both cases no material is removed from the frictional surfaces, but the particles with a higher angle of attack lead to a change from micro-ploughing to micro-cutting [27].

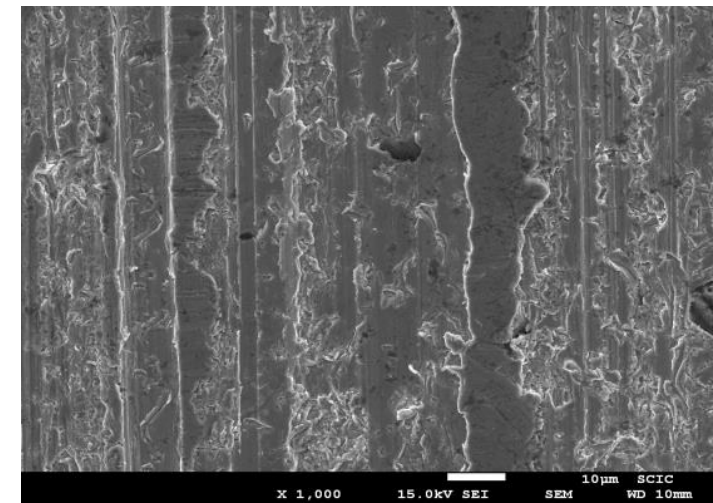

a)

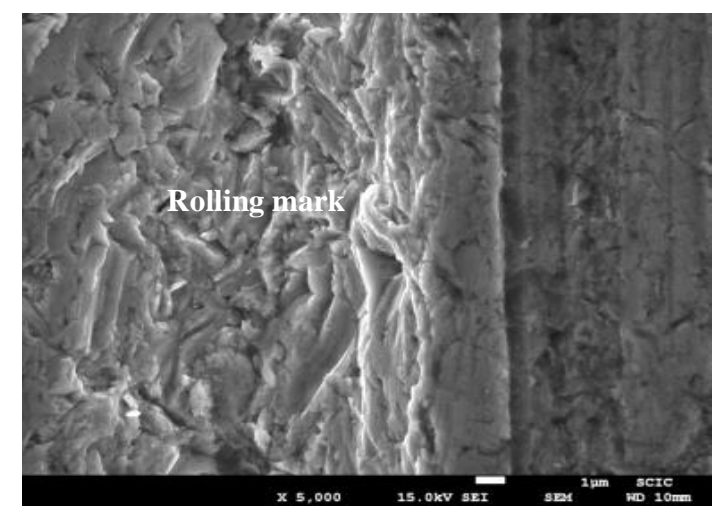

a) ${ }^{1}$

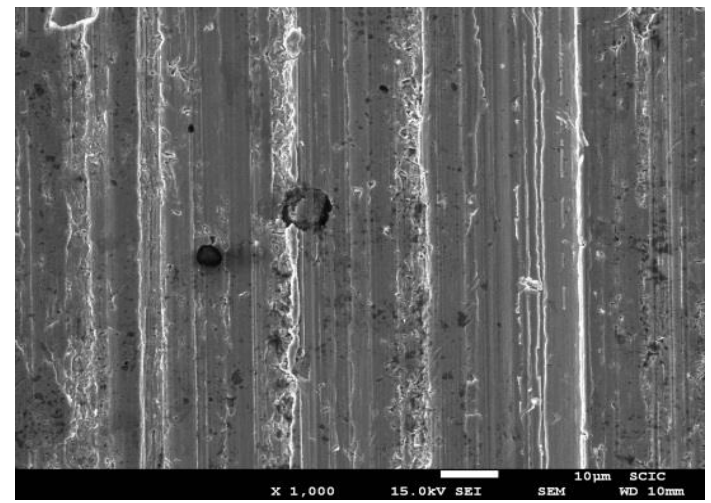

b)

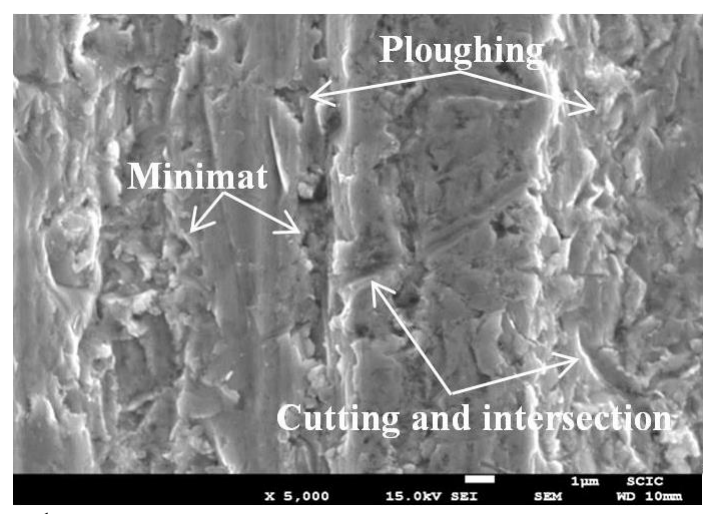

b) 1

Figure 7. SEM images of the worn surfaces: a) lubricant oil +1.5 micrometric $\mathrm{Al}_{2} \mathrm{O}_{3}(32.5 \mu \mathrm{m})$ and b) lubricant oil +1.5 micrometric $\mathrm{Al}_{2} \mathrm{O}_{3}(45 \mu \mathrm{m})$ at different magnification.

\subsection{Evaluation of coating nanoindentation after tribology tests}

To better understand the influence of the $\mathrm{Al}_{2} \mathrm{O}_{3}$ particle size on the plastic deformation behavior of the tested samples, nanoindentation of the NiCrBSi coatings was measured with a fully calibrated Algient Tech Nano Indenter G-200 nanoindentation tester using Brekovich indenter pit. Basic nanoindentations by controlling the maximum depth of $2 \mathrm{~m} \mu$ were carried out to determine the elastic and plastic work of indentation of the coating. At least twenty five measurements were taken in different zones, and the average values have been considered in this study. Table 2 shows that the change in the NiCrBSi superficial nanoindentation is because of the differences between the wear mechanisms and surface topography of the NiCrBSi coatings after the tribology tests. The nanoindentation values in the cases of lubrication with only oil and the addition of nanometric $\mathrm{Al}_{2} \mathrm{O}_{3}$ to the lubricated oil are more or less similar. The maximum 
nanoindentation values were reached by the addition of micrometric $\mathrm{Al}_{2} \mathrm{O}_{3}$ to the lubricated oil. This can be attributed to the plastic deformations caused by micrometric $\mathrm{Al}_{2} \mathrm{O}_{3}$, the compressive residual stress produced under high loads, and the increasing of strain hardening to the limit due to the increase in the particle impact energy and the rolling mechanism [28].

Table 2. Surface nanoindentation and modulus of elasticity of NiCrBSi coating after $600 \mathrm{~m}$.

\begin{tabular}{ccccc}
\hline & Solely oil & $\begin{array}{c}\text { Oil+ nanometric } \\
\mathrm{Al}_{2} \mathrm{O}_{3}(0.15 \mu \mathrm{m})\end{array}$ & $\begin{array}{c}\text { Oil+ micrometric } \\
\mathrm{Al}_{2} \mathrm{O}_{3}(32.5 \mu \mathrm{m})\end{array}$ & $\begin{array}{c}\text { Oil+ micrometric } \\
\mathrm{Al}_{2} \mathrm{O}_{3}(45 \mu \mathrm{m})\end{array}$ \\
\hline $\begin{array}{c}\text { Nanoindentation (GPa) } \\
\begin{array}{c}\text { Modulus of elasticity } \\
(\mathrm{Gpa})\end{array}\end{array}$ & 3.65 & 4.78 & 5.66 & 6.24 \\
\hline
\end{tabular}

\subsection{Friction coefficient}

The variation in the friction coefficient values for different worn surface roughness $R_{a}$ after the tribology tests are shown in Fig. 8. The results showed that the presence of $\mathrm{Al}_{2} \mathrm{O}_{3}$ particles influences the friction coefficient response and surface roughness significantly. Once the particles enter the gap between the interacting surfaces, the values and amplitude of the surface roughness tend to change with the speed and the applied load. Friction coefficient values were lower when smaller $\mathrm{Al}_{2} \mathrm{O}_{3}$ particles were used as the source of debris, as they filled up the gap between the interacting surfaces and increased the effective contact area (Fig. 9b). However, friction coefficient values for 32.5- $\mu \mathrm{m} \mathrm{Al}_{2} \mathrm{O}_{3}$ and $45-\mu \mathrm{m} \mathrm{Al}_{2} \mathrm{O}_{3}$ were higher because the bigger particles have smaller interfaces and reduce the effective contact area (Fig. 9c), which, in turn, accentuates the applied pressure, thus producing higher friction coefficient and surface roughness. Previous studies [29], [30] reported the occurrence of rolling abrasion when the friction coefficient values ranged from $\mu=0.22$ to $\mu=0.28$. In this work, the rolling abrasive friction occurred with microparticles at high loads and low speeds with friction coefficient values ranging between $\mu=0.225$ $\left(\mathrm{Al}_{2} \mathrm{O}_{3}\right.$ particle size of $\left.32.5 \mu \mathrm{m}\right)$ to $\mu=0.236\left(\mathrm{Al}_{2} \mathrm{O}_{3}\right.$ particle size of $\left.45 \mu \mathrm{m}\right)$.

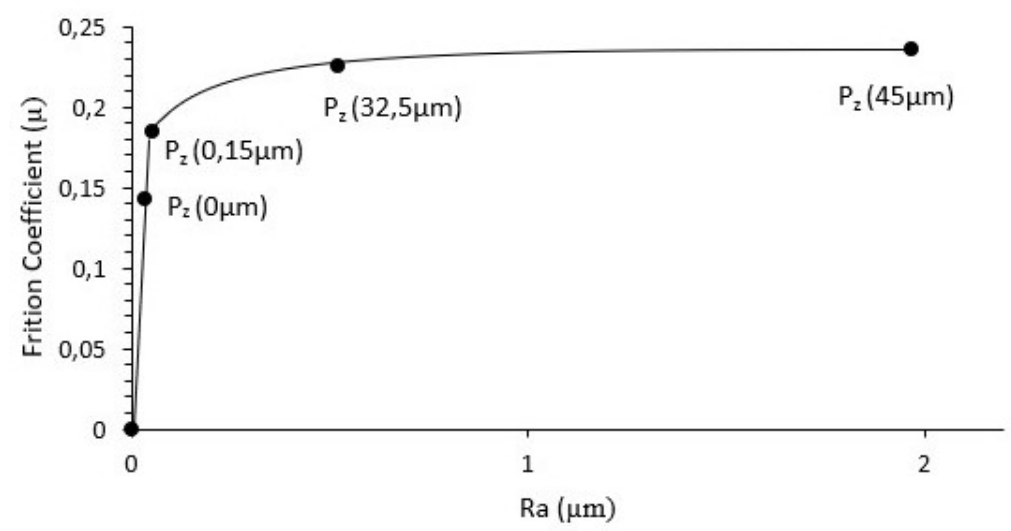


Figure 8.Variation of friction coefficient against worn surface roughness $\left(\mathrm{R}_{\mathrm{a}}\right)$ of test samples.

Under severe contact conditions (with high nominal contact pressure $\left(\mathrm{P}_{\mathrm{a}}\right)$ and velocity), a substantial increase in the friction coefficient is observed when the thickness of the lubricant layer is lower than that of the $\mathrm{Al}_{2} \mathrm{O}_{3}$ particles. The values of the friction coefficient are strongly related to the size of the particle used as the source of debris. The small friction coefficient observed when nano-particles are used might have two different/complementary explanations: a) in the case of nano-particles, the indentation geometry is small and b) in the case of nano-sized abrasive particles, clogging of the particles might reduce its detrimental effects on the wear process.
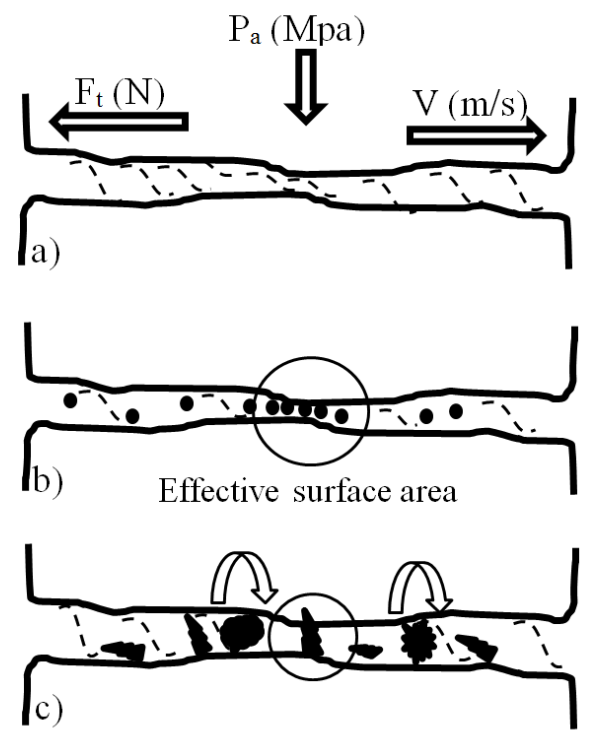

Figure 9. Diagram of a contact with debris: a) solely oil, b) oil $+1.5 \mathrm{~g}$ nanometric $\mathrm{Al}_{2} \mathrm{O}_{3}$ and c) oil $+1.5 \mathrm{~g}$ micrometric $\mathrm{Al}_{2} \mathrm{O}_{3}$.

\section{Lubrication regimes}

The Stribeck diagram is useful in analyzing the friction coefficient behavior. Traditionally, the Stribeck diagram relates the friction coefficient with a parameter (i.e., the Summerfield parameter), which includes only the viscosity of the lubricant oil, contact pressure, and sliding viscosity. Schipper proposes [31] the inclusion of a supplementary factor, namely, the initial surface roughness, Ra.

Fig. 10 summarizes the Stribeck curves for the quenched and tempered F-5220 steel coated with $\mathrm{NiCrBSi}$ via flame spraying followed by the SFM process under different conditions: solely oil, oil $+1.5 \mathrm{~g}$ of nanometric $\mathrm{Al}_{2} \mathrm{O}_{3}(0.15 \mu \mathrm{m})$, oil $+1.5 \mathrm{~g}$ of micrometric $\mathrm{Al}_{2} \mathrm{O}_{3}(32.5 \mu \mathrm{m})$, and oil $+1.5 \mathrm{~g}$ of micrometric $\mathrm{Al}_{2} \mathrm{O}_{3}(45 \mu \mathrm{m})$. As described in [32],[33] the friction coefficient was 
determined at different sliding velocities and applied loads. In the Stribeck diagram, the coefficient of friction is plotted as a function of the lubrication number proposed by Schipper, $\mathrm{Z}=\eta v / \mathrm{P}_{\mathrm{a}} \mathrm{R}_{\mathrm{a}}$ [34], which is calculated as the ratio between the sliding velocity $(v)$ and $\mathrm{P}_{\mathrm{a}}$, assuming the lubricant viscosity $(\eta)$ as constant. $\mathbf{R}_{\mathrm{ai}}$ is the arithmetic mean of the initial profile from the mean line for the tested samples. As can be observed, the lubrication number is constant for the four types of samples, i.e., it is independent of the particle size.

We have focused this investigation primarily on the evolution of friction values as a function of the $\mathrm{Al}_{2} \mathrm{O}_{3}$ particle size used as the source of debris. The differences and effects of surface

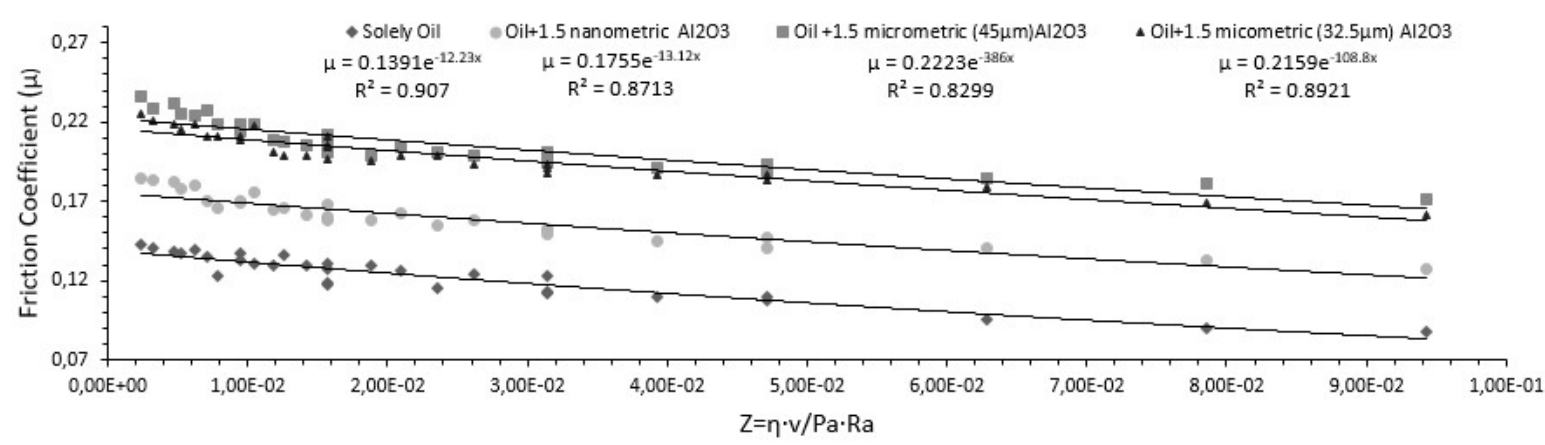

roughness on the lubrication parameters, which also need to be comprehensively discussed, are beyond the scope of this investigation and are covered elsewhere [35].

Figure 10. The Stribeck curve at different loads and sliding velocities for the friction pair F-5220 hardened steel and $\mathrm{NiCrBSi}$ coatings with solely oil, oil+nanametric $\mathrm{Al}_{2} \mathrm{O}_{3}(0.15 \mu \mathrm{m})$, micrometric $\mathrm{Al}_{2} \mathrm{O}_{3}(32.5 \mu \mathrm{m})$ and oil + micrometric $\mathrm{Al}_{2} \mathrm{O}_{3}(45 \mu \mathrm{m})$.

Table 3 shows a summary of the roughness values for these NiCrBSi pins.

Table 3. Parameters value of Stribeck curve for initial surface roughness.

\begin{tabular}{lccccc}
\hline & $\mu_{\max }$ & $\mu_{\min }$ & $\mathrm{Z}_{\text {(min) }}$ & $\mathrm{Z}_{\text {(max) }}$ & $\begin{array}{c}\mathrm{R}_{\text {a(nitial) }} \\
(\mu \mathrm{m})\end{array}$ \\
\hline Solely oil & 0.143 & 0.088 & $9.4310^{-2}$ & $2.3610^{-3}$ & 0.016 \\
Oil+1.5 nanmetric $\mathrm{Al}_{2} \mathrm{O}_{3}$ & 0.185 & 0.127 & $9.4310^{-2}$ & $2.3610^{-3}$ & 0.016 \\
Oil+1.5 micrmetric $\mathrm{Al}_{2} \mathrm{O}_{3}(32.5 \mu \mathrm{m})$ & 0.225 & 0.161 & $9.4310^{-2}$ & $2.3610^{-3}$ & 0.016 \\
Oil+1.5 micromtric $\mathrm{Al}_{2} \mathrm{O}_{3}(45 \mu \mathrm{m})$ & 0.236 & 0.171 & $9.4310^{-2}$ & $2.3610^{-3}$ & 0.016 \\
\hline
\end{tabular}


Another way to characterize the lubrication regime is by the lubrication number $K_{d}=\eta v / P_{a} R_{a f}$, where $R_{a f}$ is the final surface roughness after testing with solely oil, oil $+1.5 \mathrm{~g}$ of nanometric $\mathrm{Al}_{2} \mathrm{O}_{3}(0.15 \mu \mathrm{m})$, oil $+1.5 \mathrm{~g}$ of micrometric $\mathrm{Al}_{2} \mathrm{O}_{3}(32.5 \mu \mathrm{m})$, and oil $+1.5 \mathrm{~g}$ of micrometric $\mathrm{Al}_{2} \mathrm{O}_{3}$ $(45 \mu \mathrm{m})$. We propose the use of this parameter, $\mathrm{K}_{\mathrm{d}}$, because the lubrication regime may change substantially with changes in the sliding distance owing to changes in the surface roughness and the detachment of wear particles during the friction process. Therefore, using the final surface roughness will enable better identification of the state of the lubrication regime after the wear processes.

In laboratory studies and in some applications, it would be easy to directly measure the final surface roughness (i.e., after sliding distance of $600 \mathrm{~m}$ in our case). However, this could be impractical in most applications. Therefore, it would be interesting to find a relationship between the debris particle size, which can be analyzed online with sensors or during the maintenance operations, and the surface roughness.

Our results reveal strong dependence of the surface roughness on the particle size. An increase in the particle size changes the surface roughness, which results in a sharp rise in the friction coefficient and the wear rates. Fig. 11 shows the relationship between the particle size and surface roughness obtained after a sliding distance of $600 \mathrm{~m}$. The fitted relationship is:

$$
\mathrm{R}_{\mathrm{af}}=0.051 \mathrm{e}^{0,0779} \mathrm{P}_{\mathrm{z}}
$$

where $\mathrm{P}_{\mathrm{z}}$ is the average particle size in $\mu \mathrm{m}$.

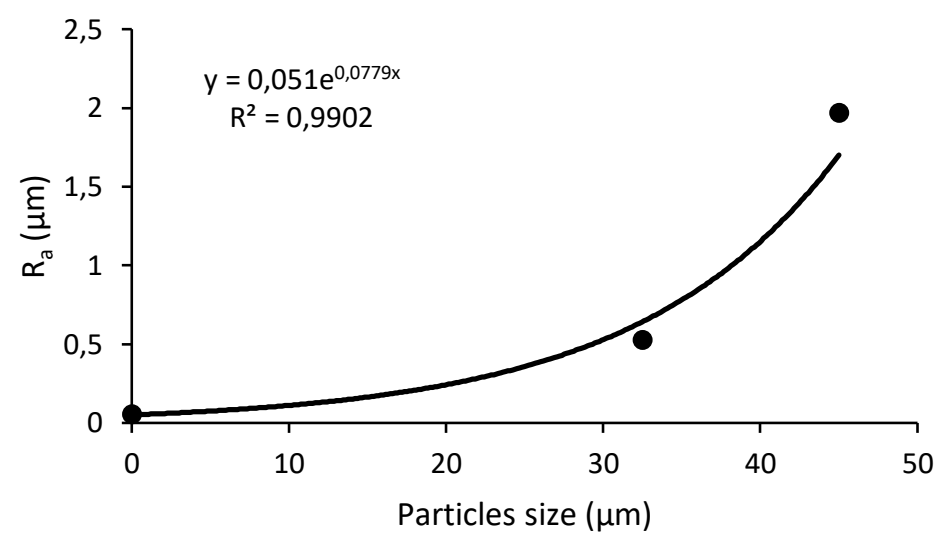

Figure 11. Correlation between particles size and surface roughness.

By including this fitted equation in the expression for the lubrication parameter, we get the following expression:

$$
\mathrm{K}_{\mathrm{d}}=\frac{\eta \cdot V}{P_{a} \cdot 0.051 e^{0.0779 \cdot P_{Z}}}
$$


Were $K_{d}$ applies when the size and amount of debris particles allow the normal operation according to the maintenance recommendation for each case.

The Stribeck curve with the new lubrication number $\left(\mathrm{K}_{\mathrm{d}}\right)$ is shown in Fig. 12. The figure shows that the lubrication number changes as a function of the particle size, which highly affects the state of the lubrication regime.

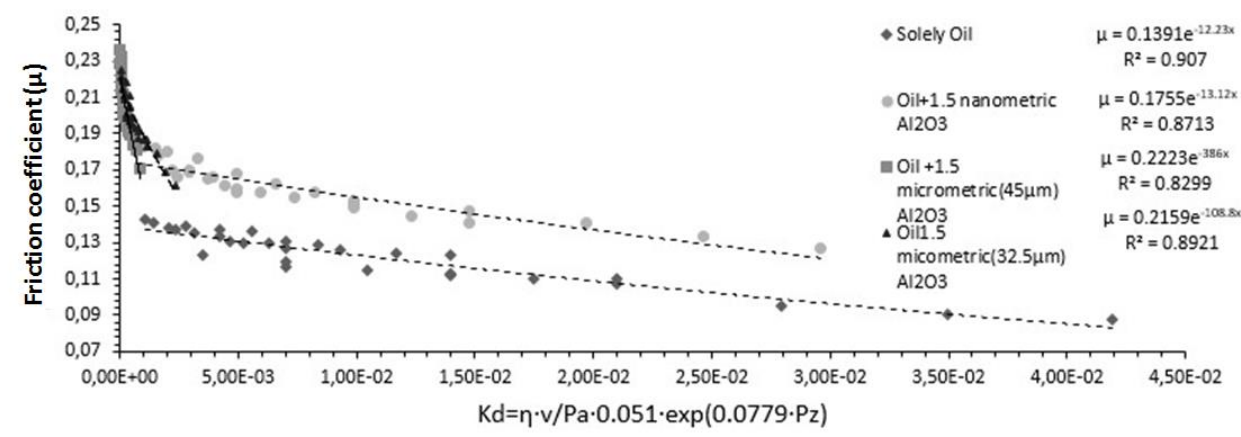

Figure 12. The Stribeck curve at different loads and sliding velocities for the friction pair after introducing the new lubrication number.

Now, by using $\mathrm{K}_{\mathrm{d}}$, it is apparent that feeding lubricant oil with different $\mathrm{Al}_{2} \mathrm{O}_{3}$ particle sizes to the contact area causes an increase in the friction coefficient and decrease in the lubrication number $\left(\mathrm{K}_{\mathrm{d}}\right)$ depending on the increase in the debris particle size. The shape of the Stribeck curve resembles an exponential shape with different inclinations for solely oil, oil $+1.5 \mathrm{~g}$ of nanometric $\mathrm{Al}_{2} \mathrm{O}_{3}(0.15 \mu \mathrm{m})$, oil $+1.5 \mathrm{~g}$ of micrometric $\mathrm{Al}_{2} \mathrm{O}_{3}(32.5 \mu \mathrm{m})$, and oil $+1.5 \mathrm{~g}$ of micrometric $\mathrm{Al}_{2} \mathrm{O}_{3}$ $(45 \mu \mathrm{m})$. Overall, the friction coefficients and the curve inclination in the case where only the lubricant was used were lower than that in the cases where $\mathrm{Al}_{2} \mathrm{O}_{3}$ was added. The minimum friction coefficient $\left(\mu_{\min }\right)$ with only the lubricant was 0.088 at $\mathrm{K}_{\mathrm{d}}=4.19 \times 10^{-2}$ and the maximum friction coefficient $\left(\mu_{\max }\right)$ was 0.143 at $\mathrm{K}_{d}=1.05 \times 10^{-3}$. However, the addition of nanometric $\mathrm{Al}_{2} \mathrm{O}_{3}$ to the lubricant oil increases $\mu_{\min }$ to 0.127 at $\mathrm{K}_{\mathrm{d}}=6.99 \times 10^{-4}$ and $\mu_{\max }$ to 0.185 at $\mathrm{K}_{\mathrm{d}}=2.79 \times 10^{-}$ ${ }^{2}$. The addition of micrometric $\mathrm{Al}_{2} \mathrm{O}_{3}(32.5 \mu \mathrm{m})$ increases $\mu_{\min }$ to 0.161 at $\mathrm{K}_{\mathrm{d}}=4.31 \times 10^{-4}$ and $\mu_{\max }$ to 0.225 at $\mathrm{K}_{\mathrm{d}}=2.87 \times 10^{-3}$. Finally, the addition of micrometric $\mathrm{Al}_{2} \mathrm{O}_{3}(45 \mu \mathrm{m})$ to the lubricant oil increases $\mu_{\min }$ to 0.171 at $\mathrm{K}_{\mathrm{d}}=7.7 \times 10^{-4}$ and $\mu_{\max }$ to 0.236 at $\mathrm{K}_{\mathrm{d}}=1.15 \times 10^{-4}$. In summary, the friction coefficient depends on the particle size dispersed in the lubricating oil and is inversely related to $\mathrm{K}_{\mathrm{d}}$.

Table 4 shows a summary of the roughness values for these NiCrBSi pins. It can be seen that there is a general trend towards higher surface roughness generated with higher particle size. 
Table 4. Parameters of Stribeck curve for each surface roughness.

\begin{tabular}{lccccc}
\hline & $\mu_{\max }$ & $\mu_{\min }$ & $\mathrm{Z}_{\text {(min) }}$ & $\mathrm{Z}_{\text {(max) }}$ & $\mathrm{R}_{\text {a(final) }}(\mu \mathrm{m})$ \\
\hline Solely oil & 0.143 & 0.088 & $4.19 .10^{-2}$ & $1.05 .10^{-3}$ & 0.036 \\
Oil+1.5 nanmetric $\mathrm{Al}_{2} \mathrm{O}_{3}(0.15 \mu \mathrm{m})$ & 0.185 & 0.127 & $2.96 .10^{-2}$ & $7.39 .10^{-4}$ & 0.054 \\
Oil+1.5 micrmetric $\mathrm{Al}_{2} \mathrm{O}_{3}(32.5 \mu \mathrm{m})$ & 0.225 & 0.161 & $8.89 .10^{-4}$ & $2.22 .10^{-5}$ & 0.525 \\
Oil+1.5 micromtric $\mathrm{Al}_{2} \mathrm{O}_{3}(45 \mu \mathrm{m})$ & 0.236 & 0.171 & $5.88 .10^{-05}$ & $2.36 .10^{-3}$ & 1.97 \\
\hline
\end{tabular}

\section{Wear behavior}

The wear volume losses of the NiCrBSi pin coating rubbed with oil only and with oil $+1.5 \mathrm{~g}$ of nanometric $\mathrm{Al}_{2} \mathrm{O}_{3}(0.15 \mu \mathrm{m})$ were lower in comparison with the pin lubricated with oil $+1.5 \mathrm{~g}$ of micrometric $\mathrm{Al}_{2} \mathrm{O}_{3}(32.5 \mu \mathrm{m})$ and oil $+1.5 \mathrm{~g}$ of micrometric $\mathrm{Al}_{2} \mathrm{O}_{3}(45 \mu \mathrm{m})$ at all studied loads and velocities (Fig. 13). This effect becomes more dominant with increase in the sliding distance, suggesting that the unfavorable effect of the $\mathrm{Al}_{2} \mathrm{O}_{3}$ particles increases with the sliding distance. At a distance of $600 \mathrm{~m}$, the volume loss of the pin lubricated with $1.5 \mathrm{~g}$ of micrometric $\mathrm{Al}_{2} \mathrm{O}_{3}$ was more than eight times higher than that of the pin lubricated with oil alone. Therefore, micrometric $\mathrm{Al}_{2} \mathrm{O}_{3}$ particles dispersed in the lubricated oil were probably attached initially to the softer NiCrBSi coatings, leading to abrasive wear of its contact area (at low speed and high loads). This resulted in severe, deeper, and wider scratching and thereby, damage of the soft NiCrBSi surface coating, which significantly increased the surface roughness values and volume loss. The ploughing effect and rolling abrasion caused by micrometric $\mathrm{Al}_{2} \mathrm{O}_{3}$ has also been shown to cause a deleterious effect on the wear of the NiCrBSi pin coating (Fig. 7b).

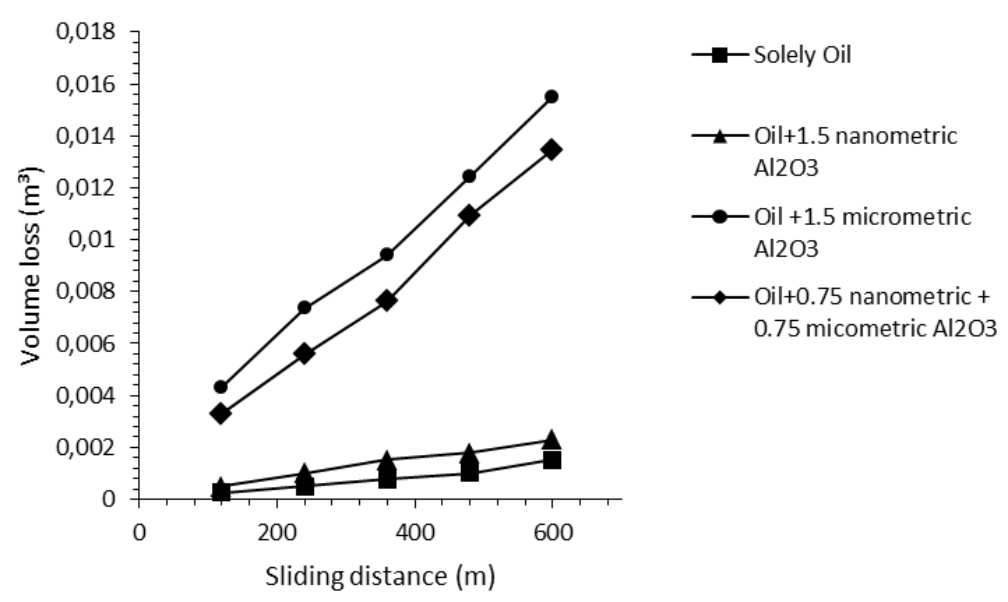

Figure 13. Accumulated wear volume at different loads and velocities of NiCrBSi coating as a function of sliding distance $(600 \mathrm{~m})$. 
In the case of lubrication with oil + nanometric $\mathrm{Al}_{2} \mathrm{O}_{3}$, part of the $\mathrm{Al}_{2} \mathrm{O}_{3}$ particles get compressed and penetrate into the surface layer of the soft NiCrBSi coating, while others first get entrapped in the surface and then get immediately removed from the sliding interface before their subsequent agglomeration (Fig. 14). These behaviors influence the wear values because of the following reasons: a) the penetration of hard particles of nanometric alumina into the comparatively softer Ni-Cr matrix increases the nanoindentation, which, in turn, lowers the damage on the wear surface by abrasion. b) The penetration of nanometric alumina with sharp edges into the coating surface creates stress concentration, which increases the hardness of the $\mathrm{NiCrBSi}$ contact surface.

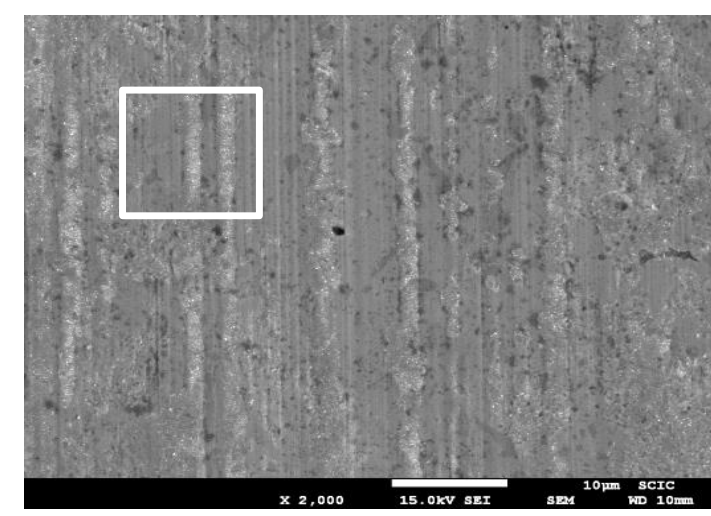

a)

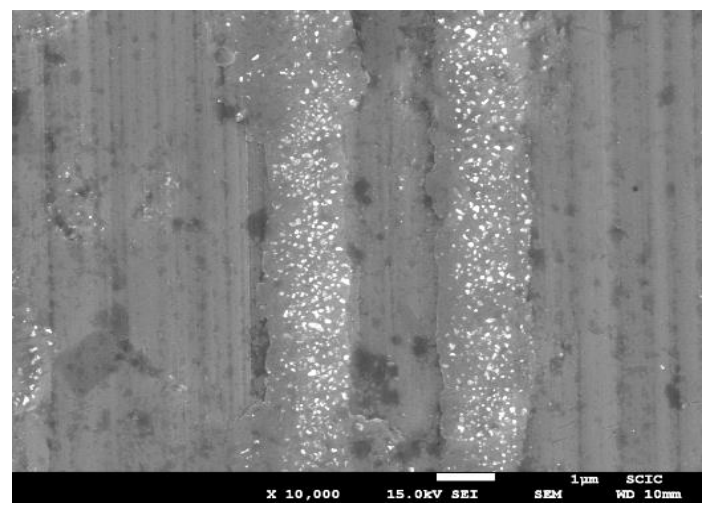

b)

Figure 14. a) SEM micrographs of nanometric $\mathrm{Al}_{2} \mathrm{O}_{3}$ particles embedded in the $\mathrm{NiCrBSi}$ coating. b) Detail view.

The representation of the averaged experimental data of the wear rates for different particle sizes after $600 \mathrm{~m}$ of exposure distance shows the increase in the wear rates with the increase in surface roughness (Fig. 15), which in turn depends on the particle size. This can be attributed to the increment in the particle kinetic energy with its size which results in higher wear rates. Additionally, severe sliding wear occurs when the conditions of high load and speed exist between the surfaces in contact. When the tension between the surfaces is very high owing to the increase in load or speed, the area in contact becomes unstable and occasionally generates debris particles, which further increases the wear rate. 
Figure 15. The dependence between wear rate and $\mathrm{Al}_{2} \mathrm{O}_{3}$ debris particles size.

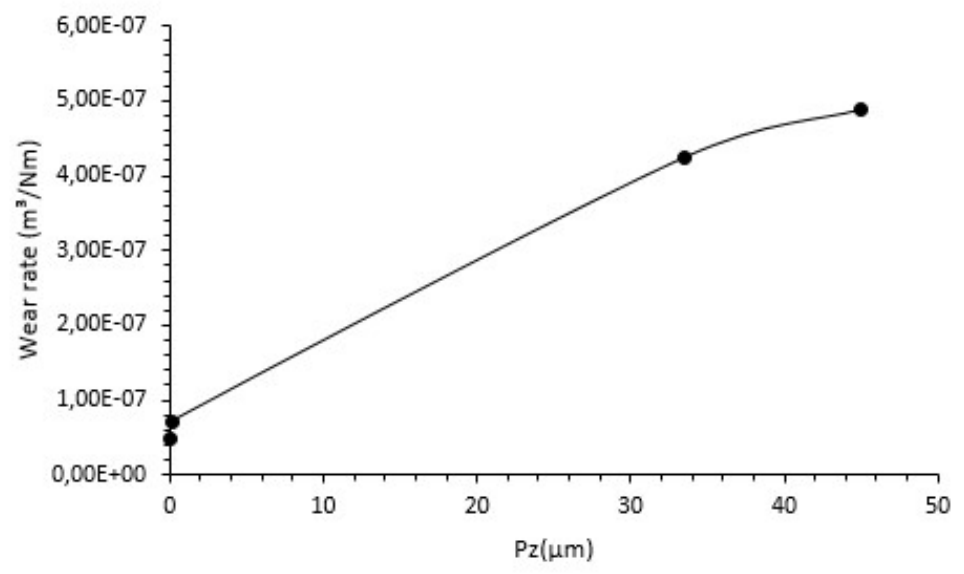




\section{Conclusions}

Empirical relationships between debris particle size and surface roughness and between surface roughness and the lubrication regime have been estimated. These relationship functions can support predictive maintenance operations for avoiding surface damage of the parts in contact. Moreover, they are useful in assessing the remaining lifetime of the friction components.

The obtained results show that the presence of abrasive debris particles dispersed in lubricated oil clearly deteriorates the tribological performance of the system, contributing to a remarkable increase in the friction coefficient and wear rate and reduction in the lubrication number with increase in the particle size.

SEM analysis of the worn surface craters revealed the presence of grooving abrasion and different degrees of rolling abrasion along the grooves depending on the particle size. Nanoindentation study after friction tests showed strain hardening of the NiCrBSi coatings due to the accumulative plastic deformation that takes place owing to repeated rolling and sliding of $\mathrm{Al}_{2} \mathrm{O}_{3}$ particles entrapped between the moving surfaces. Any increase in $\mathrm{Al}_{2} \mathrm{O}_{3}$ particle size contributes to higher values of strain hardening of the NiCrBSi coating, which presumably contributes to a significant increase in the surface nanoindentation values.

On the other hand, the experiments also show that nanometric size particles play an insignificant role in the tribology process in comparison with the micrometric particles. 


\section{References}

[1] Kalin, M., Velkavrh, I., Vižintin, J., Ožbolt, L. (2008). Review of boundary lubrication mechanisms of DLC coatings used in mechanical applications. Meccanica, 43(6), 623-637

[2] Zahid, R., Masjuki, H. H., Varman, M., Mufti, R. A., Kalam, M. A., \& Gulzar, M. (2015). Effect of lubricant formulations on the tribological performance of self-mated doped DLC contacts: a review. Tribology Letters, 58(2), 32

[3] Schamel, A. R., Grischke, M., \& Bethke, R. (1997). Amorphous carbon coatings for low friction and wear in bucket tappet valvetrains (No. 970004). SAE Technical Paper.

[4] Deschuyteneer, D., Petit, F., Gonon, M., Holmberg, K., Wäsche, R., \& Cambier, F. (2012, September). Influence of WC particle size and volume fraction on wear properties of NiCrBSi/WC coatings. In Proceedings of the 13th European Inter-Regional Conference on Ceramics, 37-40

[5] Vengudusamy, B., Grafl, A., Preinfalk, K., (2014). Influence of silicon on the wear properties of amorphous carbon under dry and lubricated conditions. Tribology Letters, 53(3), 569-583

[6] Vengudusamy, B., Green, J.H., Lamb, G.D., Spikes, H.A. (2011). Tribological properties of tribofilms formed from ZDDP in DLC/DLC and DLC/steel contacts. Tribology International, 44(2), 165-174

[7] Tasdemir, H.A., Wakayama, M., Tokoroyama, T., Kousaka, H., Umehara, N., Mabuchi, Y., Higuchi, T. (2013). Ultra-low friction of tetrahedral amorphous diamond-like carbon (ta-C DLC) under boundary lubrication in poly alpha-olefin (PAO) with additives. Tribology International, 65, 286-294

[8] Khorshid, E. A., \& Nawwar, A. M. (1991). A review of the effect of sand dust and filtration on automobile engine wear. Wear, 141(2), 349-371

[9] Khonsari, M. M., \& Wang, S. H. (1990). On the role of particulate contamination in scuffing failure. Wear, 137(1), 51-62

[10] Du, L., Xu, B., Dong, S., Yang, H., \& Tu, W. (2004). Study of tribological characteristics and wear mechanism of nano-particle strengthened nickel-based composite coatings under abrasive contaminant lubrication. Wear, 257(9-10), 1058-1063

[11] Hunt, T. M. (1993). Handbook of wear debris analysis and particle detection in liquids. Springer Science \& Business Media.

[12] Kumar, M., Shankar Mukherjee, P., \& Mohan Misra, N. (2013). Advancement and current status of wear debris analysis for machine condition monitoring: a review. Industrial Lubrication and Tribology, 65(1), 3-11

[13] Iwai, Y., Honda, T., Miyajima, T., Yoshinaga, S., Higashi, M., \& Fuwa, Y. (2010). Quantitative estimation of wear amounts by real time measurement of wear debris in lubricating oil. Tribology International, 43(1-2), 388-394

[14] Zhu, X., Zhong, C., \& Zhe, J. (2017). Lubricating oil conditioning sensors for online machine health monitoring-a review. Tribology International, 109, 473-484

[15] Flanagan, I. M., Jordan, J. R., \& Whittington, H. W. (1988). Wear-debris detection and analysis techniques for lubricant-based condition monitoring. Journal of Physics E: Scientific Instruments, 21(11), 1011. 
[16] Du, L., Zhu, X., Han, Y., \& Zhe, J. (2013). High throughput wear debris detection in lubricants using a resonance frequency division multiplexed sensor. Tribology Letters, 51(3), 453-460.

[17] Cao, W., Dong, G., Chen, W., Wu, J., \& Xie, Y. B. (2015). Multisensor information integration for online wear condition monitoring of diesel engines. Tribology international, $82,68-77$

[18] Shen, M. X., Dong, F., Zhang, Z. X., Meng, X. K., \& Peng, X. D. (2016). Effect of abrasive size on friction and wear characteristics of nitrile butadiene rubber (NBR) in two-body abrasion. Tribology International, 103, 1-11

[19] Zhu, X., Zhong, C., \& Zhe, J. (2017). Lubricating oil conditioning sensors for online machine health monitoring-a review. Tribology International, 109, 473-484

[20] Yuan, C. Q., Peng, Z., Zhou, X. C., \& Yan, X. P. (2005). The characterization of wear transitions in sliding wear process contaminated with silica and iron powder. Tribology international, 38(2), 129-143

[21] Santanam, N. (1983). Effect of wear debris on wear in rolling-sliding motion. Wear, 90(2), 261-267

[22] Blau, P. J. (1981). Mechanisms for transitional friction and wear behavior of sliding metals. Wear, 72(1), 55-66

[23] Cherif, K., Gueroult, B., \& Rigaud, M. (1997). Al2O3-ZrO2 debris life cycle during wear: effects of the third body on wear and friction. Wear, 208(1-2), 161-168

[24] Fischer, T. E., Zhu, Z., Kim, H., \& Shin, D. S. (2000). Genesis and role of wear debris in sliding wear of ceramics. Wear, 245(1-2), 53-60

[25] Schipper, D. J., Hoevenaar, A. J., De Laat, B., Bakx, S., \& Keijer, J. T. (1992). A lubrication number for mechanical seals. In Fluid Sealing (Springer, Dordrecht), 467-476

[26] T.O. Mulhearn, L.E. Samuels The abrasion of metals: a model of the process Wear, 5 (1962), pp. $478-498$

[27] Zum Gahr, K. H. (1998). Wear by hard particles. Tribology International, 31(10), 587-596

[28] Nguyen, V. B., Nguyen, Q. B., Zhang, Y. W., Lim, C. Y. H., \& Khoo, B. C. (2016). Effect of particle size on erosion characteristics. Wear, 348, 126-137.

[29] K.L. Rutherford, I.M. Hutchings. (1996). A micro-abrasive wear test, with particular application to coated systems. Surface and Coatings Technology, 79, 231-239

[30] Y. Kusano, I.M. Hutchings. (2005). Sources of variability in the free-ball micro-scale abrasion test. Wear, 258, 313-317

[31] Lu Xiaobin, M.M. Khonsari, E.R. Gelinck. (2006). The Stribeck curve: experimental results and theoretical prediction. Journal of Tribology, 128 (4) 789-794

[32] A. Moshkovich, V. Perfilyev, I. Lapsker, D. Gorni, L. Rapoport. (2011). The effect of grain size on Stribeck curve and microstructure of copper under friction in the steady friction state. Tribology Letters, 42 (1) 89-98

[33] V. Perfilyev, A. Moshkovich, I. Lapsker, L. Rapoport. (2010). Friction and wear of copper samples in the steady friction state. Tribology International, 43 1449-1456 
[34] E.R.M. Gelinck, D.J. Schipper. (2000). Calculation of Stribeck curves for line contacts. Tribology International, 33, 175-181

[35] M.D. Heresky. (1996). Theory and Research in Lubrication, Wiley, New York. 